\title{
Asymmetry and skin pigmentary anomalies in chromosome mosaicism
}

\author{
C G Woods, A Bankier, J Curry, LJ Sheffield, S F Slaney, K Smith, L Voullaire, \\ D Wellesley
}

\begin{abstract}
We report six persons mosaic for a chromosome anomaly. All were mentally retarded and dysmorphic. Unilateral or asymmetrical features were found in all cases, in one an unusual transverse terminal limb anomaly, and in the others various degrees of hemiatrophy of the left side of the body. Five of the subjects had skin pigmentary anomalies which were distributed in the lines of Blaschko. The abnormal cell lines found were ring chromosome 22, trisomy 22, a large acrocentric marker, a deletion of $18 q$, a deletion of $8 q$, and triploidy. In four cases the clinical diagnosis was only confirmed by skin biopsy. In one case low level mosaicism in blood was fortuitously detected because of cytogenetic fragile $X$ screening and confirmed in a skin biopsy. The sixth case was of dynamic mosaicism of a non-mosaic deletion 18q with a chromosome 18 derived marker present in a proportion of cells. Chromosome mosaicisn may cause subtle and asymmetrical clinical features and can require repeated cytogenetic investigations. The diagnosis should be actively sought as it enables accurate genetic counselling to be given.
\end{abstract}

( $($ Med Genet 1994;31:694-701)

It is important for the physician to be aware of the spectrum of clinical features that chromosome mosaicism can cause. As the diagnosis usually requires multiple tissue sampling they must discriminatingly select which patients to investigate. Chromosome mosaicism may present as a recognised phenotype such as PallisterKillian/12p tetrasomy, and Down's mosaicism, or as a dysmorphic intellectually disabled person often with a normal lymphocyte chromosome analysis. Whereas most chromosomal mosaics described have a symmetrical phenotype, a minority are reported to have asymmetrical and ipsilateral dysmorphic features We describe six persons mosaic for a chromosome anomaly. These are illustrative of the importance of asymmetrical features in alerting the clinician to the diagnosis and of the ease with which the confirmatory abnormal cell line may escape detection if only lymphocyte cytogenetic studies are performed.

In chromosomal mosaicism the abnormal cell line(s) contains a cytogenetically detectable chromosomal anomaly and the other cell line usually has a normal chromosome constitution. The incidence of chromosomal mosaicism causing significant phenotypic effects is un- known, but is likely to be greater than 1 in 10000 . This estimate is extrapolated from the $0.1 \%$ to $0.3 \%$ incidence of chromosomal mosaicism at amniocentesis, ${ }^{1-3}$ and that the incidence of Down's mosaics is 1.5 per 10000 (as $5 \%$ of cases are reported to be mosaics and a further $5 \%$ of cases are the result of a mitotic error $\left.^{4}\right)$. It seems likely that chromosomal mosaicism is underdiagnosed.

Mosaics and chimeras are composed of two or more cell lines. In mosaics the cell lines originate from one zygote, but in chimeras more than one zygote is involved. For the purposes of this paper, however, we use the term mosaic rather more broadly to indicate a person with two demonstrably different cell lines but not necessarily to indicate their zygotic origin.

\section{Case reports}

CASE 1

A 3 year old boy was referred because of developmental delay and a congenital malformation of the left hand, both of unknown aetiology. The parents were healthy, unrelated, Afro-Caribbeans who were normal on examination and had no scalp defects. The father was 22 years of age at the time of birth and the mother 18 years. They had no other children but the mother subsequently had a normal girl with a different partner.

The pregnancy was complicated by intermittent vaginal bleeding in the first and second trimester. The mother did not have a chorionic villus sampling. A male child was born at 38 weeks' gestation with a birth weight of $2400 \mathrm{~g}$. At birth he was noted to have an abnormal small left hand. During the first year of life three surgical procedures were undertaken to increase the function of the left hand. When seen at the age of 3 years he was assessed to be globally moderately developmentally delayed; in particular his speech was limited to a few indistinct words.

At the age of 3 years his height was $102 \mathrm{~cm}$ (90th centile) and his head circumference $51 \mathrm{~cm}$ (50th centile). He was not dysmorphic (fig 1a). There were patches of depigmentation over his entire skin surface which had been present since early infancy. He had a $1-2 \mathrm{~cm}$ wide streak of hyperpigmented skin running from the midline of his mid thoracic back to the left axilla (fig 1b). The limbs were normal apart from the left hand which had a hypoplastic thumb, fused second and third digits, and missing ulnar border (fig 1c). Neurological examination was normal.

Cytogenetic analysis of PHA stimulated 

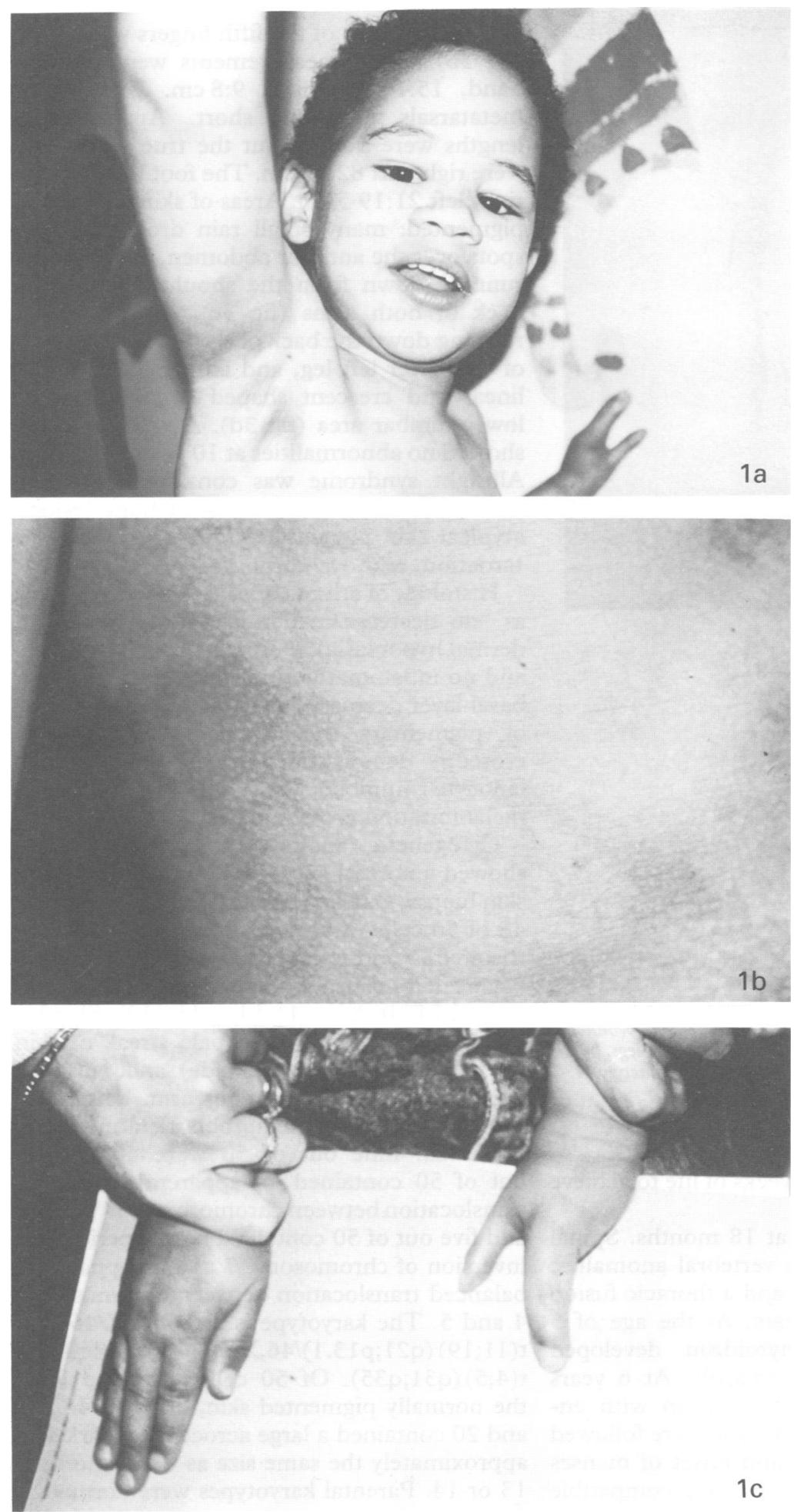

Figure 1 Case 1. (a) Face and upper body, (b) Left upper back showing a hyperpigmented skin streak radiating from the midline around to the axilla. (c) Abnormal left hand with a hypoplastic thumb, fused second and third digits, and missing ulnar border of the hand. The right hand was normal. anomalies, multiple exostoses, and moderate mental retardation, but no unifying diagnosis. A cytogenetic analysis of blood lymphocytes had been normal on two occasions. The parents were healthy, unrelated, Afro-Caribbeans, the mother being 32 and the father 31 years of age when their daughter was born. The mother had three other healthy children all by different fathers.

Pregnancy and delivery were normal and she was born at term with a birth weight of $3000 \mathrm{~g}$. She fed poorly as a neonate and at five weeks became tachypnoeic. Investigation showed a cyanotic Fallot's tetralogy. Treatment was medical and a ventricular septal defect was repaired at 11 years of age. She has attended a special school having static moderate mental retardation. Short stature was noted in the first year of life and has persisted. Bony outgrowths were noted in the second year which progressed to multiple exostoses by 4 years of age. None has caused discomfort but a thoracic lumbar scoliosis has developed. Because of increasing size, an exostosis was removed from the right fibula head at the age of 12 years. Histology confirmed a benign osteochondroma of the fibula.

On examination her height was $131 \mathrm{~cm}$ and head circumference $49 \mathrm{~cm}$, both much less than the 3rd centile. Her forehead was bossed, her ears were small, simple, and low set, her eyebrows had a lateral flair and were tented upwards, and the lower lateral eyelids were partially deficient (fig 2a). The fourth and fifth metacarpals of both hands appeared short, the middle phalanges fusiform, and the fifth finger brachydactylic (fig $2 b$ ). Over the scapula area of her right shoulder were linear hyperpigmented streaks running from her spine to her arm. Over her mid back was hyperpigmented " $U$ " and "W" shaped patterning more or less symmetrically distributed about the midline. Her left leg and foot were smaller than her right by 4 and $1 \mathrm{~cm}$, respectively. Running down the back of both her legs were linear hypopigmented streaks (fig 2c). Investigation showed a bone age of 7 years at the chronological age of 13 years. A CT brain scan was normal.

Lymphocyte karyotypes were normal, 46, $\mathrm{XX}$, on two separate examinations. A skin biopsy of normally pigmented skin showed mosaicism with $77 / 80$ cells showing a large interstitial deletion of the long arm of one chromosome 8, 46, XX, del(8) (q21q24). On detailed reanalysis of blood, one cell out of 200 examined was found to have the same deletion. Parental lymphocyte karyotypes were normal.

blood lymphocytes showed 146 cells with a normal male karyotype and five cells with an abnormal karyotype, 46,XX,r(22). The fibroblast culture from normal coloured skin showed 11 cells out of 60 to have ring chromosome 22 . Parental lymphocyte karyotypes were normal.

CASE 2

A 14 year old girl was referred for a clinical genetics opinion. She had multiple congenital

\section{CASE 3}

A 13 year old girl was referred for evaluation who had severe scoliosis, fits, precocious puberty, and mild mental retardation. The parents were healthy, unrelated, and white, both aged 20 at the time of birth. They have no other children.

The pregnancy and labour were normal and delivery was at term of a $2400 \mathrm{~g}$ female infant. Both feet were inturned, but only one required 

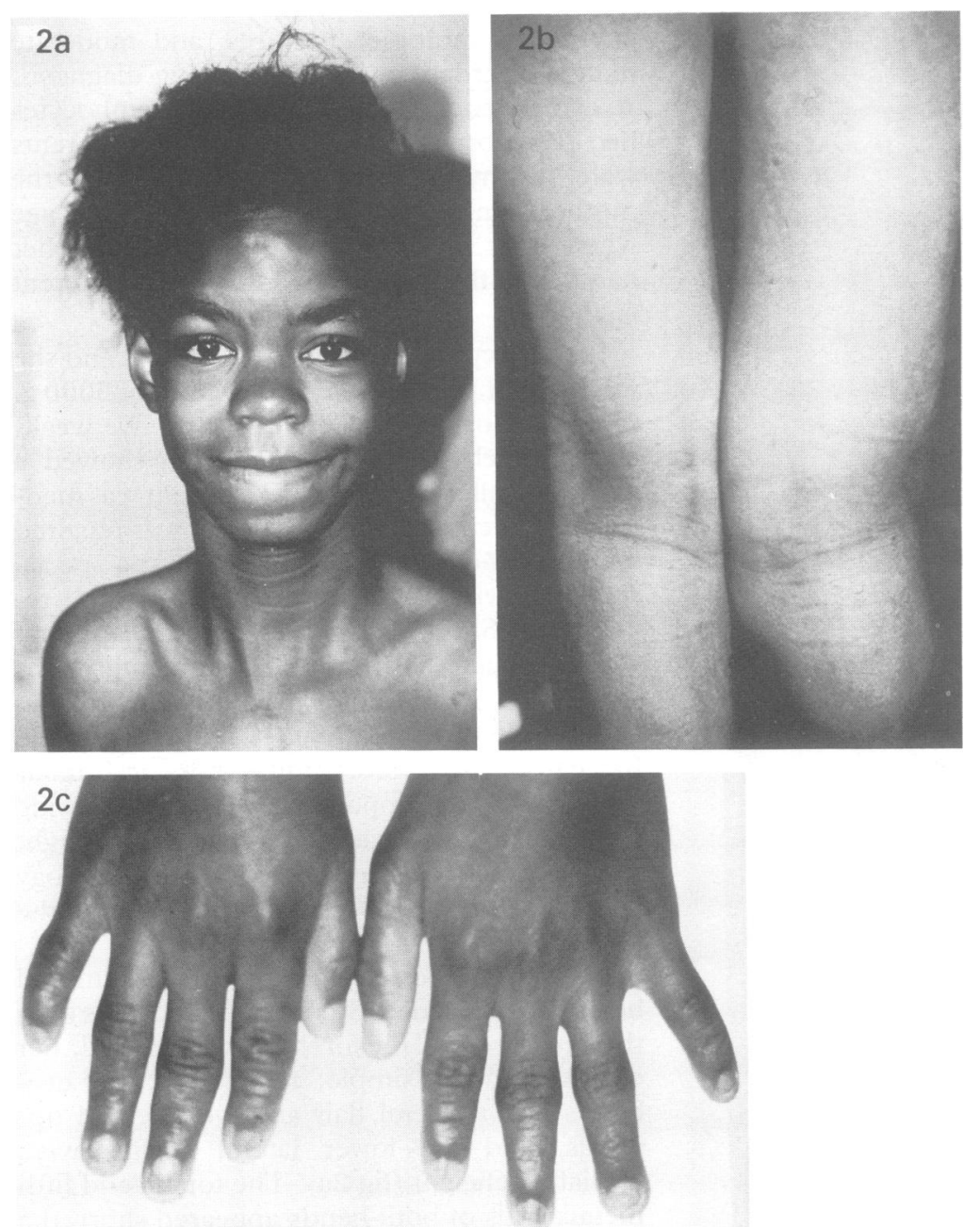

Figure 2. Case 2. (a) Dysmorphic facies showing epicanthic folds and tented eyebrows. (b) Back of the legs showing tramline hypopigmented streaks running down the legs.

(c) Hands showing brachydactyly, fusiform appearance, and fifth finger clinodactyly. and clinodactyly of the fifth fingers were noted (fig 3b). Hand measurements were right:left hand, $15: 14 \mathrm{~cm}$, palm 9:8 cm. Both fourth metatarsals appeared short. Apparent leg lengths were normal but the true leg lengths were right:left $82: 79 \mathrm{~cm}$. The foot lengths were right:left $21: 19 \cdot 5 \mathrm{~cm}$. Areas of skin were hypopigmented: many small rain drop/mud splat spots over the anterior abdomen, linear streaks running down from the shoulders along the back of both arms (fig 3c), a linear streak running down the back of the left leg and front of the lower left leg, and an area of radiating linear and crescent shaped streaks over the lower lumbar area (fig 3d). A skeletal survey showed no abnormalities at 10 years. McCuneAlbright syndrome was considered but discounted because of the lack of bone lesions, atypical skin pigmentary findings, mental retardation, and dysmorphic features.

Histology of an area of pale skin was reported as "no decrease in dermal thickness (so not dermal hypoplasia). Dermal collagen is mature and no inflammatory infiltrate. Pigment along basal layer decreased, but there is no evidence of pigmentary incontinence. Electron microscopy demonstrated no decrease in melanocyte numbers but melanosomes and melaninisation are diminished".

Cytogenetic analysis of 30 lymphocytes showed a normal karyotype, 46,XX. An initial skin biopsy, skin appearance unknown, showed 48 of 50 cells to be $46, \mathrm{XX}$ and one cell to be trisomy 21 and another to have an apparently balanced translocation involving chromosomes 11 and $14,46, \mathrm{XX}, \mathrm{t}(11 ; 14)(\mathrm{p} 11 ; \mathrm{q} 12)$. Skin biopsies were taken from a pale streak of skin on the left arm (smaller side) and normally pigmented skin on the right arm. Three cell lines were found in the fibroblast culture of the pale skin: nine out of 50 were $46, \mathrm{XX}, 36$ out of 50 contained an apparently balanced translocation between chromosomes 11 and 19 , and five out of 50 contained both a pericentric inversion of chromosome 7 and an apparently balanced translocation between chromosomes 4 and 5 . The karyotype is mos $46, \mathrm{XX} / 46, \mathrm{XX}$, $\mathrm{t}(11 ; 19)$ (q21;p13.1)/46,XX,inv(7) (p14q36), $t(4 ; 5)$ ( $q 31 ; q 35)$. Of 50 cells examined from the normally pigmented skin, 30 were $46, \mathrm{XX}$ and 20 contained a large acrocentric marker of approximately the same size as a chromosome 13 or 14. Parental karyotypes were normal. by growth of pubic hair and onset of menses at 9 years. Hormone studies were compatible with an early and sustained puberty. At 8 years her stature was on the 90th centile and her bone age was 13 years. Grand mal fits started at 6 years. At the age of 8 years absence attacks also developed. At 10 years an EEG showed a left centrotemporal focus and an MRI scan showed that the right hippocampus and left cerebellar hemisphere were mildly atrophic.

On examination at the age of 13 years her height was $138 \mathrm{~cm}$ ( $<3$ rd centile), her weight was $38 \mathrm{~kg}$ (10th to 25 th centile), and head circumference $53 \mathrm{~cm}$ (25th to 50 th centile). She had mild facial asymmetry with left sided underdevelopment, ptosis, a smooth philtrum, and absent central, upper incisors (fig 3a). There was marked scoliosis with consequent chest deformity. Bilateral short fourth fingers

\section{CASE 4}

A 3 year old girl was referred for diagnosis with developmental delay, multiple congenital anomalies and body asymmetry. Chromosome analysis showed mosaicism with 43 of 51 cells showing 46,XX,del(18)(q21q23) and eight cells showing the same karyotype with the addition of a small marker chromosome. The parents were healthy, unrelated, and white, both aged 25 at the time of their daughter's birth. They had an older daughter.

Pregnancy and birth were uneventful. Birth weight was $2700 \mathrm{~g}$ at term and resuscitation was required, but Apgar scores were 7 at five minutes and 9 at 10 minutes. Multiple con- 

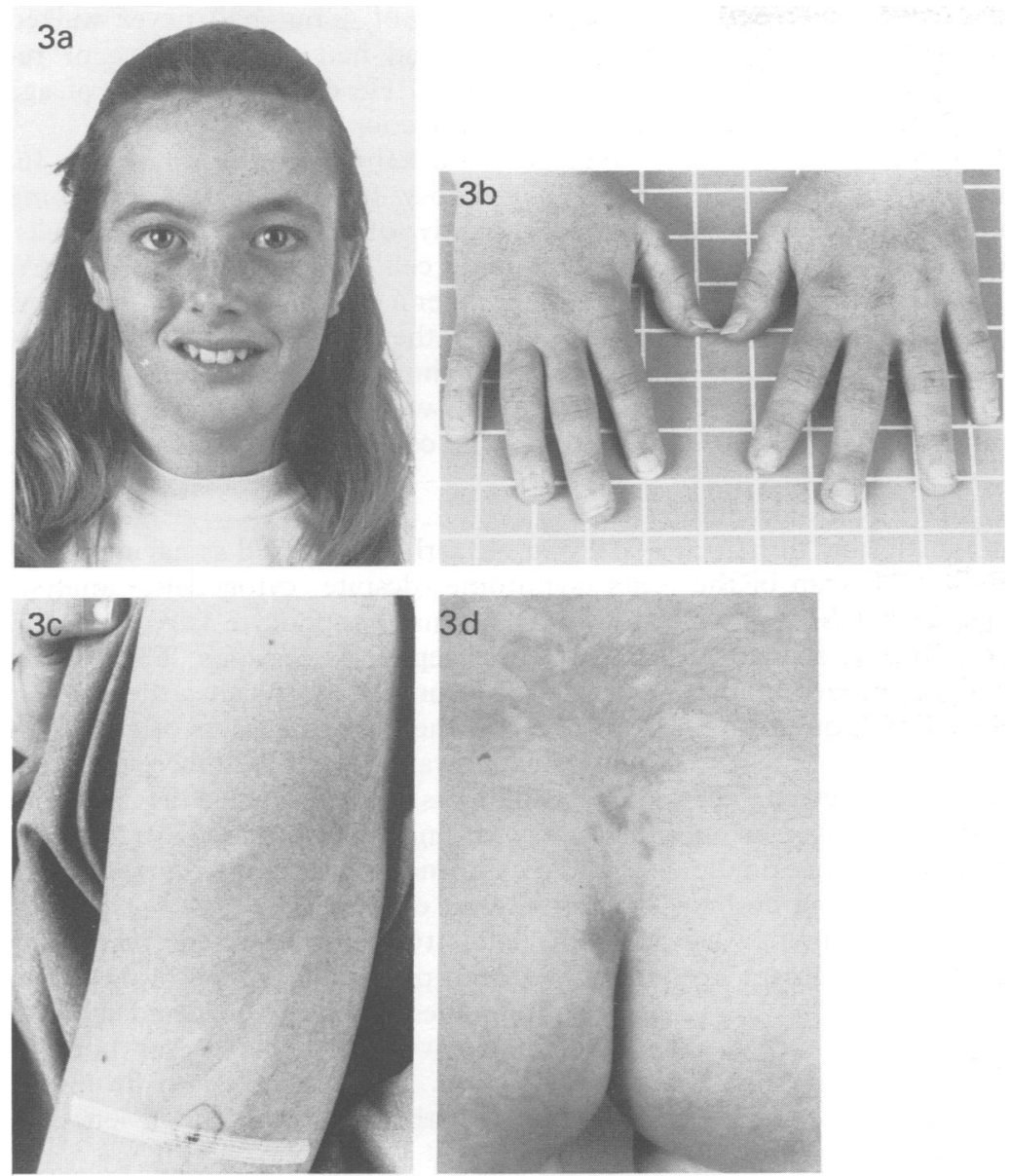

Figure 3 Case 3. (a) Facies with asymmetry caused by left sided hypoplasia. (b) Hands. Both are of the same size and show brachydactyly, short fifth metacarpals, and fifth finger clinodactyly. (c) Right upper arm showing hypopigmented linear skin streaks. (d) Lower back showing a patchy midline vascular naevus and hypopigmented streaks radiating from the midline. genital anomalies were noted. Cleft palate was repaired at $1 \frac{1}{2}$ years and a pharyngoplasty of a rigid soft palate performed at 11 years. Narrow external auditory meati and vesicular abnormalities resulted in moderate bilateral deafness. A cardiac murmur was investigated and an asymptomatic ventricular septal defect found.

In the first two years of life lateral nystagmus was evident for which no cause was found. The nystagmus gradually abated and her vision was assessed as normal. She had mild static mental retardation. Her teeth did not start erupting until 15 months and at 15 years the first dentition was not complete. Periods had not started at 15 years.

On examination at 15 years she had a mildly dysmorphic, asymmetrical face, the left side being hypoplastic. She had a brown right pupil and green left pupil. She had small hands and feet with bilateral simian creases and long tapered fingers with broad nails. She had a broad band of hyperpigmented skin about the lower abdomen, the upper margins sloping from the flanks down to the umbilicus (fig 4A). Above and parallel to the upper margin of the hyperpigmented region were a number of hyperpigmented streaks. The right leg was longer than the left, $48 \mathrm{~cm}$ compared to $81 \mathrm{~cm}$, and the right foot was larger than the left.

Cytogenetic analysis showed the same mo-

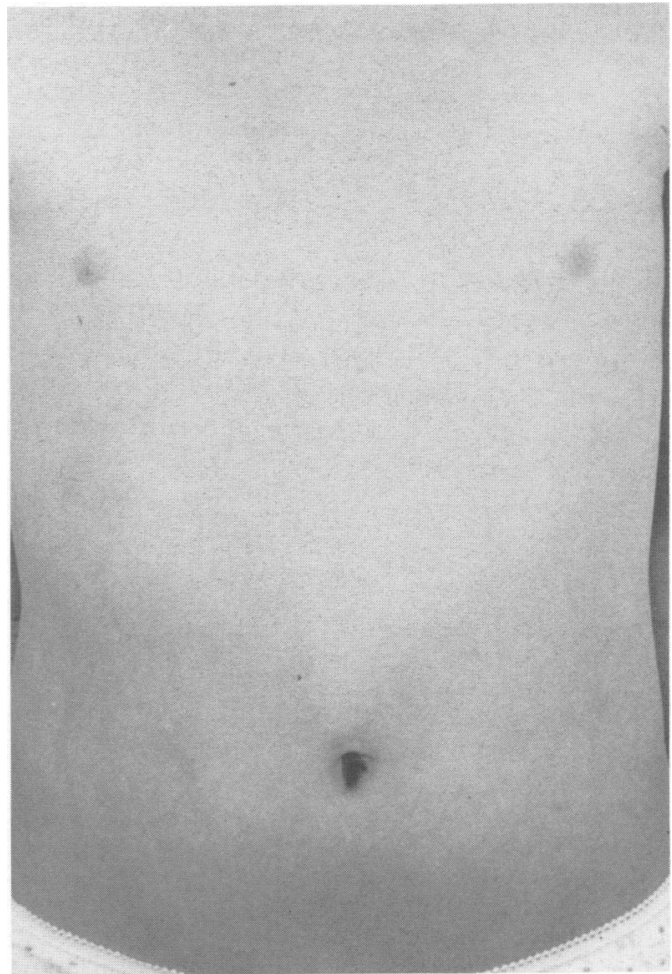

Figure 4 Case 4 showing the torso with a broad hypopigmented band around the abdomen coming down to the umbilicus from the flanks with streaking on the right upper border under the axilla.

saic karyotype at 15 years as was seen at 3 years with the marker present in six of 50 cells. Molecular cytogenetic investigations suggest that it is derived from chromosome 18 (reported elsewhere). Parental lymphocyte karyotypes were normal.

CASE 5

A boy who was severely mental retarded, short, and had asymmetrical dysmorphic features was referred for diagnosis. The parents were unrelated and white. The father was 28 years old and suffered from multiple sclerosis and the mother was 30 years old at the time of the birth of their only child.

The pregnancy was complicated by pre-eclamptic toxaemia and low oestriol levels in the third trimester. The baby was delivered by elective caesarean section at 38 weeks in good condition. Birth weight was $1450 \mathrm{~g}(<3$ rd centile), length $41 \mathrm{~cm}$ (10th centile), and head circumference was $29.4 \mathrm{~cm}$ ( 50 th centile). Dysmorphic features were noted at birth and the child remained an inpatient for three months because of failure to thrive.

He was assessed at 1 year and was on the 3rd centile for height but the 50th centile for head circumference. He had total body asymmetry with the right side being larger than the left. He had apparent macrocephaly with a large anterior fontanelle, small triangular face with frontal bossing, hypertelorism, deep set but prominent eyes with the left being smaller than the right, a big nose with a bulbous tip, thin, downturned lips, micrognathia, and large anteverted ears with flat, unfolded pinnae. He had syndactyly of the left third and fourth fingers and second and third toes. His right 
testicle was undescended. He was severely developmentally delayed and was moderately hypotonic. A skeletal survey showed generalised osteoporosis and cotton reel shaped vertebrae with narrower anterior-posterior diameters with long pedicles, likened to flying buttresses

At 3 years his anterior fontanelle was still open and the appearance of macrocephaly and body asymmetry were more marked. Grand mal epilepsy had developed as had flexion contractures of all large joints and a lumbar scoliosis. Scalp hair was sparse and his teeth were widely spaced with a number missing. Chromosome analysis of blood lymphocytes was normal on two separate analyses. A skeletal survey showed short left fourth and fifth toe phalanges and no left fibula. CT scan of the brain showed slightly increased CSF spaces around and within the brain but no structural anomalies. At 9 years a right thoracolumbar kyphosis scoliosis was treated by luque fusion from the sacrum to $T 4$.

At 10 years the patient was reviewed. His height was still on the 3rd centile, weight on the 10 th centile, and head circumference on the 50 th centile. The asymmetry and dysmorphic features are shown in fig 5 . The patient was severely mentally retarded having learnt to
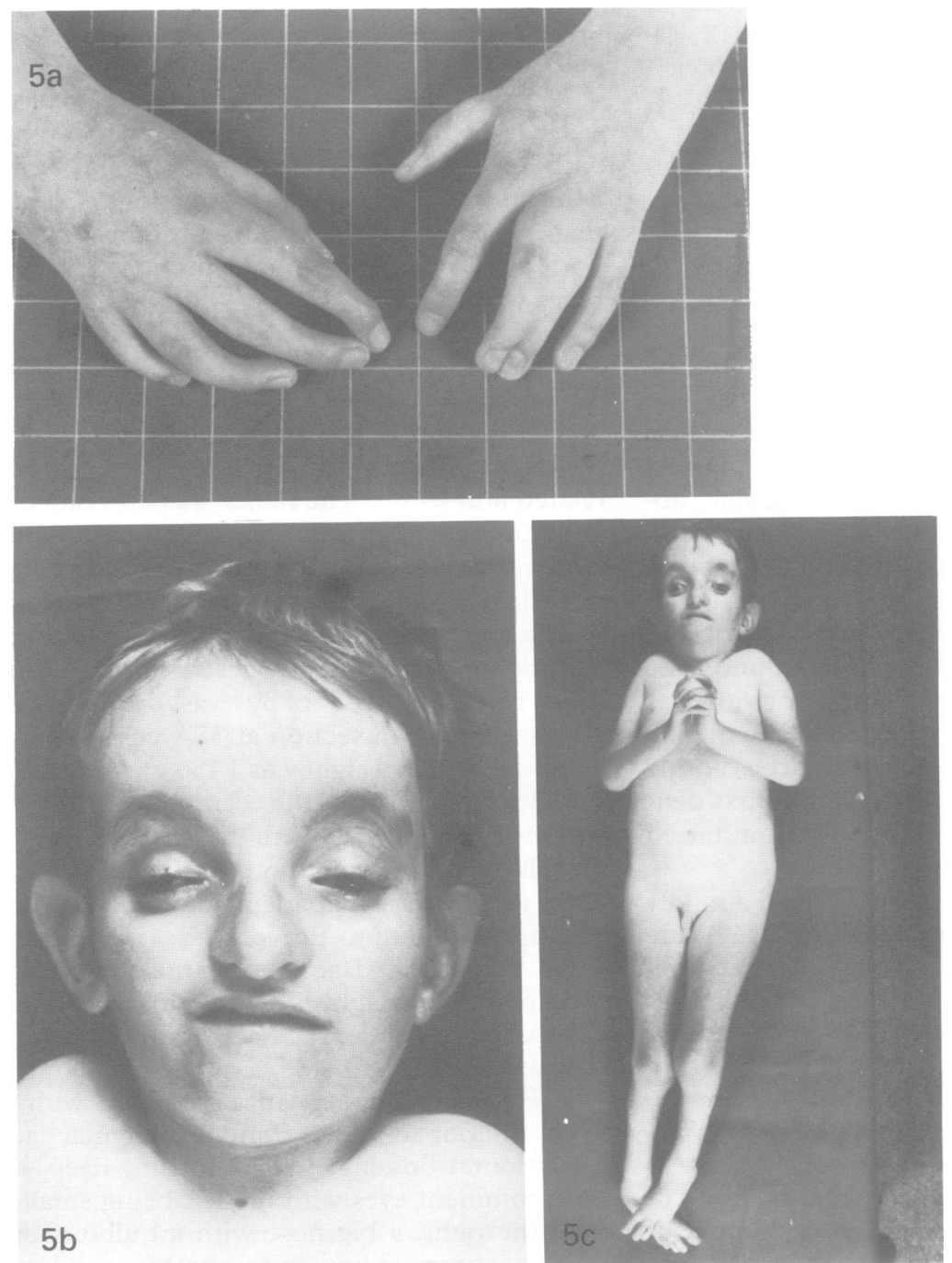

Figure 5 Case 5. (a) Both hands showing left sided 2/3 finger syndactyly. (b) Face showing deep set, prominent eyes, left sided hypoplasia. (c) View of the whole person showing the smaller left side of face, left arm, and left leg. stand at the age of 4 but had never walked independently and had no expressive or receptive language. $\mathrm{He}$ died at 15 years of age from a chest infection.

Repeat blood karyotyping was normal, 46, $\mathrm{XX}$. Skin biopsy for fibroblast karyotyping showed triploidy, $69, \mathrm{XXY}$, in 29 of 30 cells. The remaining cell had the karyotype $45, \mathrm{XY}$, -15 . The father's lymphocyte karyotype was $46, \mathrm{XY}$. The mother's lymphocyte karyotype at the age of 40 showed 42 of 50 cells were 46 , $\mathrm{XX}$, three cells were $45, \mathrm{X}$, four cells were 47 , $\mathrm{XXX}$, and one cell was $48, \mathrm{XXXX}$.

CASE 6

A 19 year old girl was referred as having Turner's syndrome despite cytogenetic analysis showing a normal lymphocyte karyotype, 46, $\mathrm{XX}$, on three separate occasions. The parents were healthy, unrelated, Asians, the mother being 38 and the father 39 years of age when their daughter was born. Of their three children, the first child was a male who died of respiratory distress syndrome at 35 weeks' gestation, the second is the index case, and the third is a healthy 17 year old female.

In the latter two months of the pregnancy there had been poor fetal growth of unknown cause. Spontaneous labour occurred at term and a female weighing $2000 \mathrm{~g}$ was born in good condition. She was noted to be mildly dysmorphic, with a murmur and a left club foot.

An asymptomatic ventricular septal defect closed spontaneously at 2 years. Left talipes equinovarus was successfully treated by tendon transfers at the age of 3 years. Severe left sided sensorineural deafness of unknown aetiology was detected at 4 years. By 5 years it was noted that her left leg was $1 \mathrm{~cm}$ shorter than her right. She had mild mental retardation, numerical calculations being particularly weak, and attended a normal school.

She was investigated at the age of 16 years because of persistent disproportionate short stature. Her right hand bone age was less than the 3 rd centile. As her left leg was shorter than her right, a leg lengthening procedure was performed at the age of 16 years. Radiological investigation at that time had confirmed her hypoplastic left leg, and to a lesser extent left arm, and also showed a shallow left acetabulum.

At the age of 18 years primary amenorrhoea was investigated. Although the diagnosis of Turner's syndrome had been suggested, cytogenetic analysis was $46, \mathrm{XX}$ on three occasions. She had high basal levels of FSH (81 $\mathrm{U} / 1)$ and LH (27 U/l) which rose even higher on an LHRH test, indicating primary ovarian failure. During an episode of acute abdominal pain a laparotomy was performed. This showed a normal vagina and cervix, and a small uterus which was unicornuate on the right side with a normal round ligament and fallopian tube but streak gonad. On the left side a small golf ball-like structure (thought to represent a vestigial hemiuterus) was found attached to a normal round ligament, vestigial fallopian tube, and a streak gonad. 
When examined at the age of 19 years she was short ( $<3$ rd centile) with a head circumference of $50.7 \mathrm{~cm}$ ( $3 \mathrm{rd}$ centile). Her left arm and leg were smaller than her right. Measurements are given as right/left in centimetres: forearm $23 / 21 \cdot 5$, upper arm $30 \cdot 3 / 29 \cdot 2$, whole hand $15 \cdot 4 / 14 \cdot 6$, palm $9 / 8 \cdot 2$, upper leg $48 / 43$, lower leg $32 \cdot 5 / 32 \cdot 5$, and foot $19 \cdot 7 / 17 \cdot 9$. She had epicanthic folds, a broad nasal bridge, downturned corners of her mouth, and a low posterior hair line. Both ears were low set. There was a right anterior ear pit. Her left sided teeth were smaller than those of the right side. The skin of her right arm was hyperpigmented in a streaky and splattered distribution running longitudinally along her arm. She had bilateral fifth finger clinobrachydactyly and there was left cutaneous syndactyly of the second and third fingers. Her left toenails were dysplastic and there was clinobrachydactyly of her left third, fourth, and fifth toes.

Fibroblast culture of hyperpigmented skin from the right arm showed 20 normal female cells and 10 with trisomy 22 . In total, 200 lymphocytes were examined, all showing a normal female karyotype. Parental karyotypes were normal.

\section{Discussion}

The clinical diagnosis of chromosomal mosaicism can be difficult and many cases are initially identified only by cytogenetic analysis. The clinical findings are diverse and include asymmetry and abnormal growth patterns, dysmorphic features, mental retardation, and skin pigmentary anomalies distributed along the lines of Blaschko (spalB). Where the skin signs are prominent the term hypomelanosis of Ito is commonly used..$^{5-9}$ Chromosome analysis of lymphocytes is often unrewarding and the abnormal cell line may only be found in other tissues of which skin is the most amenable to biopsy and analysis. The cases presented here illustrate the importance of searching for asymmetry or spalB or both when assessing a mentally retarded person.

The variable phenotypes seen in chromosome mosaicism are illustrated by our six cases. Case 1 is a child mosaic for a ring chromosome 22 . He had an unusual left hand which may have been caused by the ring chromosome 22 or a consequence of antipartum haemorrhage. No specific phenotype for ring 22 subjects has emerged but mental retardation is consistently reported. ${ }^{10} \mathrm{~A}$ previous case of mosaicism for ring chromosome 22 with spalB and moderate mental retardation but no limb anomalies has been reported. " Case 2 is a mentally retarded female with mosaic LangerGiedion syndrome (trichorhinophalangeal syndrome type II) owing to a mosaic deletion, 46, $\mathrm{XX}, \operatorname{del}(8)(\mathrm{q} 21 \mathrm{q} 24)$. This is a larger deletion than usually reported in Langer-Giedion syndrome where the hypothesised critical region is $8 \mathrm{q} 24.11$ to $8 \mathrm{q} 24.13 .{ }^{1213}$ She did not have the sparse hair, nail hypoplasia, or cone shaped epiphyses on $x$ ray described in most cases of Langer-Giedion syndrome but did have the typical facies, head, and hand appearance. ${ }^{14}$ An asymmetrical distribution of exostoses is usual in non-mosaic Langer-Giedion syndrome. Cases 3 and 6 are short, dysmorphic, mentally retarded females with multiple and asymmetrical congenital anomalies. One is probably mosaic for a large acrocentric marker and the other mosaic for trisomy 22 . Trisomy 22 is almost always reported in a mosaic form. The findings reported here are similar to other cases. ${ }^{9}$ Case 4 shows many features typical of $18 \mathrm{q}$ deletions. ${ }^{10}$ Case 5 is typical of other reports of diploid/triploid mosaicism, with $2 / 3$ syndactyly, congenital asymmetry, a large appearing head, and severe mental retardation. ${ }^{15-17}$

Asymmetrical features of growth or morphogenesis have been reported in chromosome mosaicism but are not recognised to be an important diagnostic feature. ${ }^{18-20} \mathrm{Hemi}-$ hypertrophy is the most commonly reported finding. ${ }^{21-24}$ Hemiatrophy can also occur, as illustrated by cases 3,5 , and 6 , although differentiation between hypertrophy and atrophy can be difficult. ${ }^{25}$ The cause of asymmetry is unknown but is presumably the reflection of an initial uneven distribution of the abnormal cell line in the inner cell mass or early embryo. It is noteworthy that normal ranges are poorly developed for left/right size difference comparison. ${ }^{26}$ The proportion of chromosomally mosaic persons who have significant asymmetrical features is unknown.

Skin pigmentary anomalies distributed along the lines of Blaschko are often reported in chromosome mosaicism. These are linear areas of skin differentiated from adjoining skin only by a difference in pigmentation. They are aligned along the axis of limbs and horizontally circumferentially about the trunk seeming to originate from the skin over the spinal cord. Chromosome anomalies reported with spalB include trisomy, triploidy, tetraploidy, ring chromosomes, deletions, apparently balanced translocations, and occasionally non-mosaic chromosome perturbations. ${ }^{212427-31}$ In five of six of our cases spalB was found. The lower abdominal symmetrical circumferential hyperpigmentation seen in case 4 has not been previously described but does follow the lines of Blaschko. All of our cases with pigmentary anomalies had darker skin than northern whites. Previous comments have been made that spalB is more easily detected in darker skinned races. ${ }^{2327}$ This will be particularly so if the abnormal skin in a white person is paler rather than darker than the surrounding normal skin. ${ }^{22}$ A Woods light has been reported to improve detection in white persons. ${ }^{2333-35}$ This has not been our experience and we have found incident lighting and a suntan have allowed easiest detection of spalB. Reported cases and the term hypomelanosis of Ito have emphasised that the lighter skin is abnormal. It is clear that it can either be light as in cases $1,2,3$, and 4 , or darker as in cases 1,2, and 6 (and presumably of the same hue as no cases of mosaic trisomy 21 with spalB have been reported), when compared to the normal skin. The onset of the pigmentary anomalies is recorded to be at birth in some cases of chromosome mosaicism, but not to be detected until 2 to 5 years in others, as 
in our cases. Once established the pigmentary change is stable. This is in marked contrast to the important differential diagnosis of mental retardation in persons with spalB incontinentia pigmenti where there is evolution, erythema, blistering, verucous change, hyperpigmentation, and hypopigmentation. ${ }^{36}$ Skin pigmentary dysplasia distributed along the lines of Blaschko can occur in a number of other conditions, such as in female carriers of some $\mathrm{X}$ linked disorders, like chondrodysplasia punctata and anhidrotic ectodermal dysplasia, and also mosaic distributions of single gene mutations, like McCune Albright/polyostotic fibrous dysplasia/GNAS1 mutations leading to increased activity. ${ }^{3738}$

In only two of six cases was the diagnosis of chromosome mosaicism apparent from the initial lymphocyte chromosome analysis. These findings are typical with the blood often being a poor tissue in which to search for a mosaic abnormal cell line. If detailed analysis of five lymphocytes is performed, only mosaicism of $>38 \%$ would be excluded with $90 \%$ confidence. $^{39}$

There are many reports of the abnormal cell line being only detected in fibroblasts. ${ }^{5313240-42}$ If present, the site of spalB is often used as a guide to the site for skin biopsy. This may be an erroneous assumption as the fibroblasts and melanocytes have different embryological derivations and paths of migration in the developing embryo. Skin pigmentary anomalies may be caused by melanocyte defects alone and may not be induced by fibroblast abnormalities. The lines of Blaschko are thought to represent the tracts of migration of melanocytes. ${ }^{43-45} \mathrm{Me}-$ lanocyte culture would clearly be the most desirable diagnostic modality to assess cases of suspected chromosome mosaicism with spalB, especially as both the melanocytes and neurones derive from the neural tube. Skin biopsies did not detect all cases of suspected chromosome mosaicism as illustrated by 10 of 19 persons reported by Glover et $a l^{23}$ who had blood, normal skin, and hypopigmented skin examined cytogenetically, ${ }^{23}$ and five of 13 persons described by Sybert et $a l^{5}{ }^{5}$ and in two further cases we investigated who were mentally retarded and dysmorphic with asymmetrical features and spalB. Biopsies at more than one skin site may be required to show the abnormal cell line or to show that it is not just a cultural artefact. ${ }^{46}$ Usually, however, the mosaic cell line is present in similar proportions at different sites of sampling. ${ }^{23}$ Keratinocyte cultures have recently been shown to be of use in detecting covert chromosome mosaicism, confirming one case detected by fibroblast culture showing a hitherto undetected trisomy 7 cell line but failing to find an XY/X0 mosaic line present in fibroblasts. ${ }^{38}$

The findings of a number of different but apparently balanced translocations in case 3 is an unusual finding, but has been previously reported in chromosome mosaicism. ${ }^{478} \mathrm{We}$ are unsure whether the clincal features are caused by the chromosome mosaicism or are the consequence of an undiagnosed primary defect. Similar cytogenetic findings have also been reported in incontinentia pigmenti and Werner's progeria syndrome. ${ }^{49}$ Subjects with significant mental retardation, microcephaly, and mosaicism for multiple different aneuploidies have been described. This entity is thought to be an autosomal recessive disorder of mitosis. ${ }^{5051}$

The finding of chromosome mosaicism has implications for the individual subject and family. The value of knowing a specific diagnosis in a child with intellectual disabilities and multiple malformations is obvious. A diagnosis not only clarifies the patient's management but definitely helps to alleviate the guilt so common to parents who wonder whether they have caused the birth defects by some omission or commission during the pregnancy. An exact prediction of phenotype is not possible as the proportion of the abnormal cell line in one tissue may give little guidance to its recurrence in other tissues, for instance the brain..$^{52}$ For the families, given that the parents have normal cytogenetic analyses and that multiple different aneuploides were not found, recurrence risk is small.

We would like to thank Dr J Hurst for allowing us to report one of her patients and Professor D M Danks, Dr R J M Gardner, and V Petrovic for helpful comments in the preparation of this manuscript.

1 Bui TH, Iselius L, Lindsten J. European collaborative study on prenatal diagnosis. Prenat Diagn 1984;4:145-62.

2 Hsu LYF, Perilis T. United States survey on chromosome mosaicism and pseudomosaicism in prenatal diagnosis. Prenat Diagn 1984;4:97-130.

3 Worton RG, Stern R. A Canadian collaborative study of mosaicism in amniotic fluid cell cultures. Prenat Diagn 1984;4:131-44.

4 Antonarakis SE. Human chromosome 21: genome mapping and exploration circa 1993. Trends Genet 1993;9:142-8.

5 Sybert VP, Pagon RA, Donlan M, Bradley CM. Pigmentary abnormalities and mosaicism for chromosomal aberrations: association with clinical features similar to hy pomelanosis of Ito. F Pediatr 1990;115:581-6.

6 Lenzini E, Bertoli P, Artifoni L, Battistella PA, Baccichetti C, Peserico A. Hypomelanosis of Ito: involvement of chromosome aberrations in this syndrome. Ann Genet (Paris) 1991;34:30-2.

7 Flannery DB, Byrd JR, Freeman WE, Perlman SA. A cutaneous marker of chromosome mosaicism. Am $\mathrm{f} \mathrm{Hum}$ Genet 1985;37:A93.

8 Ritter CL, Steele MW, Wenger SL, Cohen BA. Chromosome mosaicism in hypomelanosis of Ito. Am $\mathcal{F}$ Med Genet 1990; 35:14-17.

9 Takematsu H, Sato S, Igarashi $M$, Seiji M. Incontinentia pigmenti achromians. Arch Dermatol 1983;119:391-4.

pigmenti achromians. Arch Dermatol 1983;119:391-4.
10 Schinzel A. A catalogue of unbalanced chromosome aberrations in man. Berlin: de Gruyter, 1983:618-19.

11 Ritter CL, Steele MW, Wenger SL, Cohen BA. Chromosome mosaicism in hypomelanosis of Ito. $\mathrm{Am} \mathcal{f} \mathrm{Med}$ Genet 1990;35:14-17.

12 Bühler EM, Bühler UK, Beutler C, Fessler R. A final word on the tricho-rhino-phalangeal syndromes. Clin Genet 1987;31:273-5.

13 McKusick V. Mendelian inheritance in man. 10th ed. Baltimore: Johns Hopkins University Press, 1992:558-60.

14 Langer LO, Krassikoff N, Laxova R, et al. The trichorhinophalangeal syndrome with exostoses (or Langer Giedion syndrome). Am $\mathcal{F}$ Med Genet 1984;19:81-111.

15 Ellis JR, Marshal R, Normand ICS, Penrose LS. A girl with triploid cells. Nature 1963;4076:411

16 Graham JM, Hoegin H, Lin MS, Smith DW. Diploid/ triploid mixoploidy: clinical and cytognetic aspects. $\mathrm{Pe}$ diatrics $1981 ; 68: 23-8$.

17 Jenkins ME, Eisen J, Sequin F. Congenital asymmetry and diploid/triploid mosaicism. Am 7 Dis Child 1971;122:80-4. 18 Hunter AGW, Clifford B, Cox DM. The characteristic physiognomy and tissue specific karyotype distribution in physiognomy and tissue specific karyotype distribution in 19 Johnson VP, Acheto T Jr, Likness C. Trisomy 14 mosaicism: case report and review. Am $\mathcal{f}$ Med Genet 1979;3:331-9.

20 Editorial. Hypomelanosis of Ito. Lancet 1992;339:651-2.

21 Miller CA, Parker WD. Hypomelanosis of Ito: association with a chromosome abnormality. Neurology 1985;35:60710

22 Grazia R, Tullini A, Rossi PG, et al. Hypomelanosis of Ito with trisomy 18 mosaicism. Am $\mathcal{F}$ Med Genet 1993;45: $120-1$

23 Glover MT, Brett EM, Atherton DJ. Hypomelanosis of Ito: spectrum of disease. $\mathcal{F}$ Pediatr 1989;115:75-80. 
24 Wulfsberg EA, Wassel WC, Polo CA. Monozygotic twin girls with diploid/triploid chromosome mosaicism and cutaneous pigmentary dysplasia. Clin Genet 1991;39:370 5.

25 Papenhausen PR, Mueller OT, Bercu B, Salazar J, Tedesco TA. Cell line segregation in a 45, X/46, XY mosaic child

26 Hall JG Froster-Iskenius UG Allanson JE Handbook of normal physical measurements. Oxford: Oxford University Press, 1989.

27 Thomas IT, Frias JL, Cantu ES, Lafer CZ, Flannery DB, Graham JG. Association of pigmentary anomalies with Graham JG. Association of pigmentary anomalies with chromosomal and genetic mosaic

28 Vormittag W, Ensinger E, Raff M. Cytogenetic and dermatoglyphic findings in a familial case of hypomelanosis of toglyphic findings in a familial

29 Kelly TE, Rart JM. Mosaic tetraploidy in a two year old female. Clin Genet 1974;6:221-4.

30 Dennis NR, Collins AL, Crolla JA, Cockwell AE, Fisher AM, Jacobs PA. Three patients with ring $(X)$ chromosomes and a severe phenotype. $\mathcal{F}$ Med Genet 1993;30:482-6.

31 Donnai D, McKeown C, Andrews J, Read AP. Diploid triploid mixoploidy and hypomelanosis of Ito. Lancet 1986; i: $1443-4$

32 Stanley WS, Powell CM, Devine GC, et al. Mosaic $5 \mathrm{p}$ tetrasomy. Am ₹ Med Genet 1993;45:774-6.

33 Turleau C, Taillard F, Doussau de Bazignan M, Delépine $\mathrm{N}$, Desbois JC, de Grouchy J. Hypomelanosis of Ito. Hum Genet 1986;74:185-7.

34 Fleury P, Dingemanns K, de Groot WP, et al. Ito's hypomelanosis. A review of four cases. Clin Neurol Neurosurg pomelanosis.

35 Scwartz MF, Esterly NB, Fretzin DF, Pergament E, Rozenfeld IH. Hypomelanosis of Ito: a neurocutaneous syndrome. F Pediatr 1977;90:236-40.

36 Landy SJ, Donnai D. Incontinentia pigmenti. $f$ Med Gene 1993;30:53-9.

37 Gorlin RJ. Conference report of the 2nd R J Gorlin Dysmorphology Meeting. Clin Dysmorphol 1994;2:278-82.

38 Moss C, Larkins S, Stacey M, Blight A, Farndon PA Davison EV. Epidermal mosaicism and Blaschko's lines. $\mathcal{f}$ Med Genet 1993;30:752-5.
39 Hook EB. Exclusion of chromosome mosaicism: table of $90 \% 95 \%$ and $99 \%$ confident limits and comments on their use. Am $\mathcal{F}$ Hum Genet 1977;29:94-7.

40 Rott HD, Ulmer R, Haneke E. Hypomelanosis of Ito and chromosomal mosaicism in fibroblasts. Lancet 1986;ii: 343.

41 Miller PR, Parkin CA, Frazer N, Watt JL. Case of diploid/ triploid chimerism. $₹$ Med Genet 1988;25:128A.

42 Jenkins D, Martin K, Young ID. Hypomelanosis of Ito associated with mosaicism for trisomy 7 and apparent pseudomosaicism at amniocentesis. $\mathcal{F}$ Med Genet 1993;30: p83-4.

43 Jackson $R$. The lines of Blaschko: a review and reconsideration. Br $\mathcal{f}$ Dermatol $1976 ; 95: 349-60$.

44 Blaschko A. Die Nevenverteilung in der Haut in ihren Beziehung zu den Ekrankungen der Haut. Beilage zu den Beziehung zu den Ekrankungen der Haut. Beilage zu den Verhandlung der Deutschen Derme.

45 Happle R. Lyonization and the lines of Blaschko. Hum Genet 1985;70:200-6.

46 Chitayat D, Friedman JM, Johnston MM. Hypomelanosis of Ito - a non-specific marker of somatic mosaicism. $A m$ f Med Genet 1900;35:422-4

47 Akefeldt A, Gillberg C. Hypomelanosis of Ito in three case with autism and autism-like conditions. Dev Med Child Neurol 1991;33:737-43.

48 Miller CA, Parker WD. Hypomelanosis of Ito: association with chromosomal anomalies. Neurology 1985;35:607-10.

49 Iancy T, Komlos L, Shabtay F, Elian E, Halbrecht I, Book JA. Incontinentia pigmenti. Clin Genet 1975;7:103-10.

50 Tolmie JL Boyd E, Batstone P, Fenguson-Smith ME, A Roomi L, Connor JM. Siblings with chromosomal mosaicism, microcephaly, and growth retardation: the phenotypic expression of a human mitotic mutant? Hum Genet otypic expression

51 Miller K, Muller W, Winkler L, Hadam MR, Ehrich JHH, Flatz SD. Mitotic disturbance associated with mosaic aneuploidies. Hum Genet 1990;84:361-4.

52 Kingston HM, Nicolini U, Haslam J, Andrews T. 46,XY/ $47, X Y,+17 p+$ mosaicism in amniocytes associated with fetal abnormalities despite normal fetal blood karyotype. Prenat Diagn 1993;13:637-42. 